\title{
Physiotherapy management of patients undergoing lumbar spinal surgery: a survey of Australian physiotherapists
}

\author{
Sarah J Gilmore BPhty
}

Physiotherapist, St Vincent's Private Hospital Melbourne, Australia; Department of Rehabilitation, Nutrition and Sport, College of Science, Health and Engineering, La Trobe University, Melbourne, Australia

Jodie A McClelland PhD

Department of Rehabilitation, Nutrition and Sport, College of Science, Health and Engineering, La Trobe University, Melbourne, Australia

\section{Megan Davidson PhD}

Department of Rehabilitation, Nutrition and Sport, College of Science, Health and Engineering, La Trobe University, Melbourne, Australia

\section{ABSTRACT}

Physiotherapists are commonly involved in the management of patients immediately before and after spinal surgery, however there is currently little known about what constitutes physiotherapy intervention in the hospital setting. This research aimed to describe the current physiotherapy practice in Australia for the peri-operative management of adults undergoing lumbar spinal surgery. A telephone survey was conducted using a structured questionnaire format. All Australian hospitals that admit one or more patients per week for lumbar spinal surgery were invited to take part in the survey. Sixty-four interviews were conducted (response rate 79\%). All participating hospitals provided a physiotherapy service for patients undergoing lumbar spinal surgery, with the majority commencing the day following surgery. Physiotherapy intervention consistently included mobility and functional task training, exercise prescription and provision of an educational handout. However, there was considerable variability in the type of exercises prescribed, the advice given regarding post-operative movement and activity restrictions, the use of outcome measurement tools, and referral to inpatient and outpatient physiotherapy services. This survey provides physiotherapists and rehabilitation service providers with information regarding current clinical practice, and identifies the key focus areas for future research into the effectiveness of specific physiotherapy interventions.

Gilmore S, McClelland J, Davidson M (2016) Physiotherapy management of patients undergoing lumbar spinal surgery: a survey of Australian physiotherapists. New Zealand Journal of Physiotherapy 44(2): 105-112. doi: 10.15619/NZJP/44.2.06.

Key words: Physiotherapy, Survey, Spinal fusion, Discectomy, Laminectomy

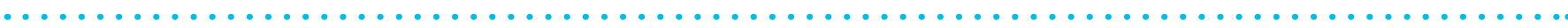

\section{INTRODUCTION}

Physiotherapists are commonly involved in the management of patients in the peri-operative period, immediately before and after spinal surgery (Rushton et al 2014, Williamson et al 2007). Research carried out in the United Kingdom has found that the focus of peri-operative physiotherapy is typically on the provision of information related to the surgery and ensuring patient readiness for safe discharge. However, the timing of intervention, the number of sessions with a physiotherapist, and the specific interventions provided are all highly variable (Rushton et al 2014, Williamson et al 2007).

While there is a growing body of evidence that rehabilitation interventions commenced four to six weeks following surgery improve patient outcomes, there is little research to guide physiotherapists in designing effective rehabilitation programmes in the peri-operative period (Gilmore et al 2015, Oosterhuis et al 2014). The rate of spinal fusion surgery in Australia increased by 175\% between 1997 and 2006 (Harris and Dao 2009). A similar increase of $137 \%$ was demonstrated in the United States between 1999 and 2008, with an associated 3.3-fold increase in total hospital charges and a 7.9-fold increase in the total national bill for spinal fusion surgery (Rajee et al 2008). As a result, it is becoming increasingly important for physiotherapists to have access to high quality research that assists with the development of clinically effective and cost effective interventions that optimise patient outcome.

There is currently little known about physiotherapy services provided to patients undergoing spinal surgery in Australian hospitals, including the percentage of hospitals that routinely provide pre and post-operative physiotherapy, and the specific interventions provided. To ensure future research is focused on physiotherapy goals and interventions commonly provided in the clinical setting, an understanding of current physiotherapy practice within Australian hospitals is required.

This research aimed to describe the current peri-operative physiotherapy management of adults undergoing lumbar spinal surgery in Australia. The specific research questions addressed are: a) What constitutes current physiotherapy practice in the pre-operative and post-operative inpatient setting, for the management of adults undergoing lumbar spinal surgery in Australia? b) Is there variation in physiotherapy practice between the different types of lumbar surgery? c) How do 
individual surgeons' protocols and preferences influence current physiotherapy practice? d) How prevalent is the use of standardised outcome measures, and which measures are most commonly used?

\section{METHODS}

\section{Design}

A telephone survey using a structured questionnaire format was employed (Appendix 1). The survey was designed to gain a broad, descriptive overview of physiotherapy interventions within a 20 to 30 minute interview. Direct, closed ended questions with pre-determined response categories were based on previous surveys investigating the management of lumbar spinal surgery patients in the UK (McGregor et al 2006, Williamson et al 2007). The survey was piloted on three members of the target population prior to use (Gideon 2012) with minor alterations made to the response categories and structure of the questionnaire. The questionnaire consisted of two sections - General Information (hospital and physiotherapist demographics), and Physiotherapy Intervention. The Physiotherapy Intervention section was divided into seven sub-sections - provision of physiotherapy service, timing and frequency of physiotherapy, advice and education, mobility and functional tasks, exercise, physiotherapy following discharge from the acute setting, and outcome measurement. For each sub-section, participants were asked if physiotherapy intervention varied based on surgical procedure (microdiscectomy, discectomy, laminectomy or fusion) or individual surgeon preferences. If variation existed the sub-section was completed for each variation. A single interviewer conducted all interviews. This study was approved by the La Trobe University Human Ethics Research Committee (FHEC13/146).

\section{Participants}

All Australian hospitals that admit one or more patients per week for lumbar spinal surgery were invited to take part in the survey. Hospitals with a neurosurgical and/or orthopaedic service were identified using the MyHospitals website (accessed May 2013). An information package was posted to the physiotherapy department of each hospital. Contact with the hospital physiotherapy department was then made by telephone to determine eligibility, and to obtain the contact details of the senior physiotherapist responsible for the management of patients undergoing lumbar spinal surgery. Up to four attempts were made to contact the appropriate physiotherapist at each hospital. All participants gave informed consent prior to taking part in the survey.

\section{Data analysis}

Data were entered into an excel spreadsheet and were analysed using descriptive statistics. Data were analysed for each surgical procedure (laminectomy, micro-discectomy, discectomy, fusion). As laminectomy surgery was the only surgical procedure conducted at all of the participating hospitals, the results of physiotherapy interventions before and after laminectomy surgery are reported, with data for other procedures reported only where physiotherapy service/intervention varied on the basis of procedure. Where within hospital variation in physiotherapy intervention based on individual surgeon preferences was present, each variation has been treated as an additional response. The total numbers reported $(\mathrm{N})$ have been adjusted to reflect the presence of within-hospital variation in intervention.

\section{RESULTS}

\section{Participants}

A total of 81 hospitals that admitted patients for lumbar spinal surgery were identified and 64 telephone interviews were conducted (79\% response rate) between August and December 2013. Of the 17 hospitals that did not participate, two declined. Initial telephone contact was made with the appropriate physiotherapist at two hospitals who were unable to be subsequently contacted to complete the survey. The appropriate physiotherapist was unable to be contacted at the remaining 13 hospitals. Of the 17 hospitals that did not participate three (18\%) were publicly funded.

The demographics of the participating hospitals and physiotherapists are described in Table 1. All 64 hospitals admitted patients for laminectomy surgery. Ninety five percent (61/64) admitted patients for fusion surgery, $91 \%$ (58/64) for discectomy surgery and 89\% (57/64) for micro-discectomy surgery. More than one surgeon performed lumbar spinal surgery at $84 \%(54 / 64)$ of the participating hospitals. Either the structure of the physiotherapy service or the content of the physiotherapy intervention varied based on individual surgeon preferences at just over half $(54 \%, 29 / 54)$ of those hospitals.

\section{Table 1: Hospital and physiotherapist demographics $(n=64)$}

\begin{tabular}{ll}
\hline Hospital Demographics & $\mathrm{n}(\%)$ \\
\hline $\begin{array}{l}\text { Funding } \\
\quad \text { Public }\end{array}$ & $31(48 \%)$ \\
$\quad$ Private & $33(52 \%)$ \\
Weekly admissions for lumbar & \\
surgery & \\
$1-10$ & $47(73 \%)$ \\
$>10$ & $17(27 \%)$ \\
Surgical procedures undertaken & \\
$\quad$ Micro-discectomy & $57(89 \%)$ \\
$\quad$ Discectomy & $58(91 \%)$ \\
Laminectomy & $64(100 \%)$ \\
$\quad$ Fusion & $61(95 \%)$ \\
\hline
\end{tabular}

Physiotherapist Demographics

Employment arrangement Employed directly by hospital $52(81 \%)$ External physiotherapy service $12(19 \%)$

Gender

$\begin{array}{ll}\text { Female } & 41(64 \%) \\ & 23(36 \%)\end{array}$

Male

12 (SD 8.80; range 3-40)

Mean years of experience Physiotherapist 8 (SD 5.48; range 1-25)

Notes: SD, standard deviation. 
The overall results of this survey demonstrated very little variation in patient management based on the surgical procedure. Minor differences were reported in the provision of service pre-operatively with patients undergoing lumbar fusions, and post-operatively with undergoing micro-discectomy surgery. The physiotherapy interventions provided also did not differ based on surgical procedure, with only minor differences in exercise prescription. Detailed results are described below.

Pre-operative physiotherapy

A pre-operative physiotherapy service was provided at 39\% (25/64) of the hospitals either in a pre-admission clinic (46\%, $12 / 25$ ) or following admission to hospital (54\%, 14/25) (Figure 1). All patients undergoing all lumbar spinal surgery procedures were seen pre-operatively by a physiotherapist at 11\% (7/64) of hospitals, with an additional two hospitals providing a preoperative physiotherapy service only to patients undergoing lumbar fusion surgery. Where a pre-operative physiotherapy service was not provided or only some patients were seen prior to surgery, the most common reason was a lack of opportunity due to the patient preadmission or admission process.

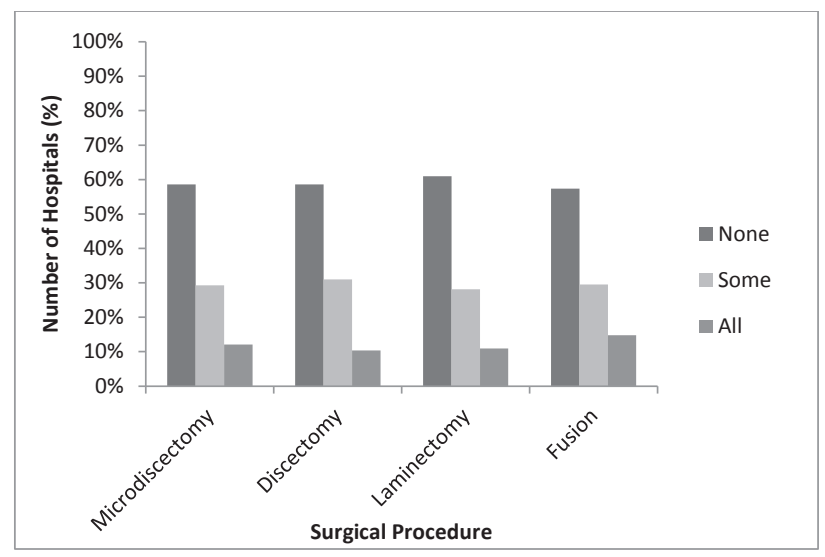

Figure 1: Provision of pre-operative physiotherapy service
The predominant focus of pre-operative physiotherapy was on patient education. Of the hospitals that provided a pre-operative service, 36\% (9/25) assessed patient mobility and 12\% (3/25) included demonstration of the post-operative exercise programme. No hospitals provided pre-operative exercise or rehabilitation programmes.

Post-operative physiotherapy

All hospitals provided physiotherapy intervention following laminectomy, discectomy and fusion surgery. Two respondents reported patients were not routinely seen following microdiscectomy surgery - in one case patients were seen on a referral only basis, and in the other patients did not receive any physiotherapy intervention due to surgeon preferences.

The timing and frequency of physiotherapy intervention is described in Table 2. At more than $97 \%$ of the hospitals, physiotherapy commenced the day following laminectomy, discectomy and fusion surgery, while seven hospitals (12\%, $7 / 57$ ) provided an initial physiotherapy contact on the day of surgery for patients undergoing a micro-discectomy. Patients were most commonly seen once per day $(80 \%, 51 / 64)$, while the total number of treatment sessions provided varied between the four surgical procedures. Although physiotherapy generally commenced the day following surgery, 23\% (15/66) allowed patients to mobilise the day of surgery following laminectomy, discectomy or fusion surgery, and just under half $(41 \%, 24 / 59)$ allowed patients to mobilise on the day of micro-discectomy surgery. 
Table 2. Post-operative physiotherapy service

\begin{tabular}{|c|c|c|c|c|c|c|c|c|c|}
\hline \multirow[b]{2}{*}{ Initial physiotherapy contact } & \multirow[b]{2}{*}{ DOS } & \multicolumn{2}{|c|}{$\begin{array}{l}\text { Microdiscectomy } \\
(n=57)\end{array}$} & \multicolumn{2}{|c|}{$\begin{array}{l}\text { Discectomy } \\
(n=58)\end{array}$} & \multicolumn{2}{|c|}{$\begin{array}{l}\text { Laminectomy } \\
(n=64)\end{array}$} & \multicolumn{2}{|c|}{$\begin{array}{l}\text { Fusion } \\
(n=61)\end{array}$} \\
\hline & & 7 & $(12 \%)$ & 2 & $(3 \%)$ & 2 & $(3 \%)$ & 1 & $(2 \%)$ \\
\hline & D1 & 50 & $(88 \%)$ & 56 & $(97 \%)$ & 62 & $(97 \%)$ & 60 & $(98 \%)$ \\
\hline \multirow[t]{3}{*}{ Contacts per day } & One & 47 & $(82 \%)$ & 46 & $(79 \%)$ & 51 & $(80 \%)$ & 48 & $(79 \%)$ \\
\hline & Two & 10 & $(18 \%)$ & 12 & $(21 \%)$ & 13 & $(20 \%)$ & 12 & $(20 \%)$ \\
\hline & Three+ & - & & - & & - & & 1 & $(2 \%)$ \\
\hline \multirow{4}{*}{ Total no. of contacts } & One/two & $45^{\mathrm{a}}$ & $(76 \%)$ & $23^{b}$ & $(38 \%)$ & $17^{c}$ & $(26 \%)$ & $8^{d}$ & $(13 \%)$ \\
\hline & Three/four & $9^{a}$ & $(15 \%)$ & $25^{b}$ & $(42 \%)$ & $31^{c}$ & $(47 \%)$ & $29^{d}$ & $(45 \%)$ \\
\hline & Five/six & $3^{a}$ & $(5 \%)$ & $6^{b}$ & $(10 \%)$ & $11^{c}$ & $(17 \%)$ & $13^{d}$ & $(20 \%)$ \\
\hline & Seven+ & $2^{a}$ & $(3 \%)$ & $6^{\mathrm{b}}$ & $(10 \%)$ & $7^{c}$ & $(11 \%)$ & $14^{d}$ & $(22 \%)$ \\
\hline \multirow{4}{*}{$\begin{array}{l}\text { First allowed to mobilise as } \\
\text { per surgical protocol }\end{array}$} & DOS & $24^{a}$ & $(41 \%)$ & $12^{b}$ & $(20 \%)$ & $15^{c}$ & $(23 \%)$ & $13^{e}$ & $(19 \%)$ \\
\hline & D1 & $35^{a}$ & $(59 \%)$ & $47^{b}$ & $(78 \%)$ & $50^{c}$ & $(73 \%)$ & $49^{e}$ & $(73 \%)$ \\
\hline & D2 & - & & $1^{\mathrm{b}}$ & $(2 \%)$ & $1^{c}$ & $(2 \%)$ & $4^{e}$ & (6\%) \\
\hline & D3+ & - & & - & & - & & $1^{e}$ & $(1 \%)$ \\
\hline
\end{tabular}

Notes: Total numbers include variations in surgical preferences where reported, ${ }^{a} n=59 ;{ }^{b} n=60 ;{ }^{c} n=66$; ${ }^{d} n=64 ;$ e $n=67 ;$ DOS, day of surgery; $D 1$, first post-operative day; D2, second post-operative day; D3, third post-operative day.

\section{Advice and education}

The majority of hospitals provided patients with a written handout $(85 \%, 55 / 65)$. No respondents reported providing education in any additional format such as video or online resources.

Advice regarding post-operative restrictions varied between hospitals (Figure 2). Variation in post-operative restrictions within hospitals related to individual surgeon preferences rather than the surgical procedure being undertaken. Most respondents $(82 \%, 60 / 73)$ reported patients were advised to avoid lifting, with a mean weight restriction of $2.7 \mathrm{~kg}$ (SD 1.50; range 0.5 5). Fifty-eight percent (43/74) of respondents advised patients to restrict sitting in the post-operative period, with the mean maximum advised sitting time being 25 minutes (SD 15.6; range 0-60).

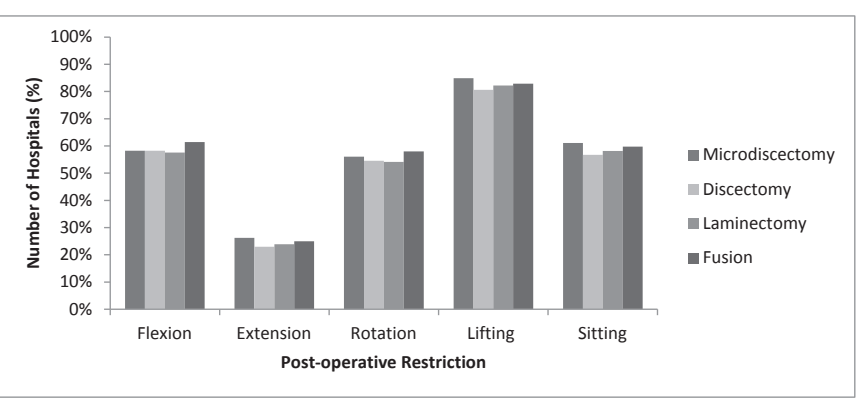

\section{Figure 2: Post-operative restrictions}

\section{Mobility and functional tasks}

All participating hospitals provided post-operative education and training in bed and chair transfers and ambulation, and most $(86 \%, 55 / 64)$ routinely practised ambulating on stairs prior to discharge. A small number of respondents reported that post- operative physiotherapy included practising picking up objects from the floor $(5 \%, 3 / 64)$, transfers on and off the floor $(5 \%$, $3 / 64)$ and on and off the toilet $(3 \%, 2 / 64)$, and ambulating outdoors $(2 \%, 1 / 64)$.

\section{Exercise prescription}

Post-operative exercises were prescribed at $88 \%$ (56/64) of the hospitals. A total of 56 different exercises were described which were subsequently grouped into seven exercise categories: core stability, spinal range of motion (ROM), stretches, strengthening (lower limb and trunk), neural mobilisation, lower limb circulation, and respiratory exercises. A complete list of the exercises described has been provided in Table 3.

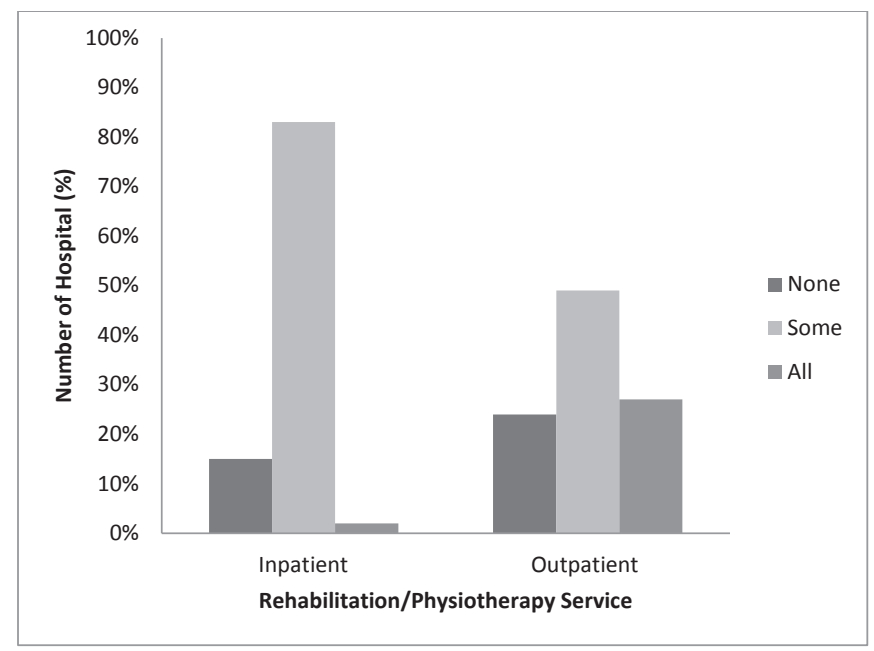

Figure 3: Referral to inpatient and outpatient physiotherapy/rehabilitation services 


\begin{tabular}{|c|c|c|c|c|}
\hline & $\begin{array}{l}\text { Microdiscectomy } \\
n^{*}=50\end{array}$ & $\begin{array}{l}\text { Discectomy } \\
\mathrm{n}^{*}=50\end{array}$ & $\begin{array}{l}\text { Laminectomy } \\
\mathrm{n}^{*}=56\end{array}$ & $\begin{array}{l}\text { Fusion } \\
n^{*}=53\end{array}$ \\
\hline $\begin{array}{l}\text { Core Stabilisation: } \\
\text { TA activation (CL) } \\
\text { Pelvic floor activation } \\
\text { TA activation (st) } \\
\text { TA activation (sit) } \\
\text { Hip abduction (CL) } \\
\text { TA activation (sit to st) }\end{array}$ & $\begin{array}{l}45(90 \%) \\
8(16 \%) \\
4(8 \%) \\
4(8 \%) \\
1(2 \%) \\
1(2 \%)\end{array}$ & $\begin{array}{l}44(88 \%) \\
9(18 \%) \\
3(6 \%) \\
3(6 \%) \\
- \\
-\end{array}$ & $\begin{array}{l}50(89 \%) \\
9(16 \%) \\
4(7 \%) \\
4(7 \%) \\
1(2 \%) \\
1(2 \%)\end{array}$ & $\begin{array}{l}47(89 \%) \\
8(15 \%) \\
4(8 \%) \\
3(6 \%) \\
1(2 \%) \\
1(2 \%)\end{array}$ \\
\hline $\begin{array}{l}\text { LL circulation: } \\
\text { Ankle pumps } \\
\text { Static quadriceps } \\
\text { Hip/knee flexion } \\
\text { Static gluteals }\end{array}$ & $\begin{array}{l}19(38 \%) \\
14(28 \%) \\
9(18 \%) \\
5(10 \%)\end{array}$ & $\begin{array}{l}22(44 \%) \\
18(36 \%) \\
11(22 \%) \\
8(16 \%)\end{array}$ & $\begin{array}{l}25(45 \%) \\
19(34 \%) \\
11(20 \%) \\
8(14 \%)\end{array}$ & $\begin{array}{l}26(49 \%) \\
21(40 \%) \\
11(21 \%) \\
9(17 \%)\end{array}$ \\
\hline $\begin{array}{l}\text { Strengthening: } \\
\text { Mini squats } \\
\text { Heel raises (st) } \\
\text { Hip abduction (st) } \\
\text { Bridging } \\
\text { Hip flexion (st) } \\
\text { Hip extension (st) } \\
\text { Hip abduction (SL) } \\
\text { Inner range quads } \\
\text { Marching on spot } \\
\text { Squats } \\
\text { Step ups } \\
\text { Mini lunge } \\
\text { Hip flexion (sit) } \\
\text { Knee extension (sit) } \\
\text { Hip adduction (sit) } \\
\text { Sit to stand } \\
\text { Static abdominal contraction } \\
\text { Hip extension (prone) } \\
\text { Pulsing abdominal contraction } \\
\text { Static trunk extension } \\
\text { Side stepping }\end{array}$ & $\begin{array}{l}10(20 \%) \\
9(18 \%) \\
7(14 \%) \\
6(12 \%) \\
6(12 \%) \\
4(8 \%) \\
4(8 \%) \\
3(6 \%) \\
3(6 \%) \\
2(4 \%) \\
2(4 \%) \\
1(2 \%) \\
1(2 \%) \\
1(2 \%) \\
1(2 \%) \\
1(2 \%) \\
1(2 \%) \\
1(2 \%) \\
1(2 \%) \\
1(2 \%) \\
-\end{array}$ & $\begin{array}{l}11(22 \%) \\
8(16 \%) \\
7(14 \%) \\
5(10 \%) \\
5(10 \%) \\
4(8 \%) \\
4(8 \%) \\
3(6 \%) \\
3(6 \%) \\
2(4 \%) \\
2(4 \%) \\
1(2 \%) \\
1(2 \%) \\
1(2 \%) \\
1(2 \%) \\
1(2 \%) \\
1(2 \%) \\
1(2 \%) \\
1(2 \%) \\
1(2 \%) \\
1(2 \%)\end{array}$ & $\begin{array}{l}11(20 \%) \\
10(18 \%) \\
7(13 \%) \\
7(13 \%) \\
6(11 \%) \\
4(7 \%) \\
4(7 \%) \\
4(7 \%) \\
3(5 \%) \\
2(4 \%) \\
2(4 \%) \\
1(2 \%) \\
1(2 \%) \\
1(2 \%) \\
1(2 \%) \\
1(2 \%) \\
1(2 \%) \\
1(2 \%) \\
1(2 \%) \\
1(2 \%) \\
1(2 \%)\end{array}$ & $\begin{array}{l}10(19 \%) \\
9(17 \%) \\
8(15 \%) \\
6(11 \%) \\
7(13 \%) \\
4(8 \%) \\
4(8 \%) \\
3(6 \%) \\
3(6 \%) \\
3(6 \%) \\
2(4 \%) \\
1(2 \%) \\
1(2 \%) \\
1(2 \%) \\
1(2 \%) \\
1(2 \%) \\
1(2 \%) \\
1(2 \%) \\
1(2 \%) \\
1(2 \%) \\
1(2 \%)\end{array}$ \\
\hline $\begin{array}{l}\text { Spinal ROM: } \\
\text { Lumbar rotation (supine) } \\
\text { Hip flexion (supine) } \\
\text { Pelvic tilt (supine) } \\
\text { Pelvic tilt (st) } \\
\text { Pelvic tilt with hip flex (supine) } \\
\text { Pelvic tilt against wall } \\
\text { Pelvic tilt (sit) } \\
\text { Side flexion (sit) }\end{array}$ & $\begin{array}{l}16(32 \%) \\
10(20 \%) \\
7(14 \%) \\
2(4 \%) \\
1(2 \%) \\
1(2 \%) \\
1(2 \%) \\
1(2 \%)\end{array}$ & $\begin{array}{l}16(32 \%) \\
9(18 \%) \\
8(16 \%) \\
1(2 \%) \\
1(2 \%) \\
1(2 \%) \\
1(2 \%) \\
1(2 \%)\end{array}$ & $\begin{array}{l}18(32 \%) \\
11(20 \%) \\
9(16 \%) \\
2(4 \%) \\
1(2 \%) \\
1(2 \%) \\
1(2 \%) \\
1(2 \%)\end{array}$ & $\begin{array}{l}14(26 \%) \\
11(21 \%) \\
8(15 \%) \\
1(2 \%) \\
1(2 \%) \\
1(2 \%) \\
1(2 \%) \\
1(2 \%)\end{array}$ \\
\hline $\begin{array}{l}\text { Neural mobilisation: } \\
\text { Straight leg raise } \\
\text { Hip flex with knee flex/ext (supine) } \\
\text { Ankle df with C ext/pf with C flex (sit) } \\
\text { Hip flex, knee ext, ankle df (st) } \\
\text { Femoral glide (SL) } \\
\text { Supine chin to chest } \\
\text { Hip and knee flex (st) } \\
\text { Heel over step with ankle pf/df (st) } \\
\text { Active assisted hip ROM (supine) } \\
\text { Hip ROM (st) } \\
\text { Modified slump }\end{array}$ & $\begin{array}{l}4(8 \%) \\
3(6 \%) \\
3(6 \%) \\
2(4 \%) \\
1(2 \%) \\
1(2 \%) \\
1(2 \%) \\
1(2 \%) \\
1(2 \%) \\
1(2 \%) \\
1(2 \%)\end{array}$ & $\begin{array}{l}4(8 \%) \\
4(8 \%) \\
3(6 \%) \\
2(4 \%) \\
2(4 \%) \\
1(2 \%) \\
1(2 \%) \\
1(2 \%) \\
1(2 \%) \\
1(2 \%) \\
1(2 \%)\end{array}$ & $\begin{array}{l}5(9 \%) \\
4(7 \%) \\
3(5 \%) \\
2(4 \%) \\
2(4 \%) \\
1(2 \%) \\
1(2 \%) \\
1(2 \%) \\
1(2 \%) \\
1(2 \%) \\
1(2 \%)\end{array}$ & $\begin{array}{l}5(9 \%) \\
4(8 \%) \\
3(6 \%) \\
2(4 \%) \\
2(4 \%) \\
1(2 \%) \\
1(2 \%) \\
1(2 \%) \\
1(2 \%) \\
1(2 \%) \\
1(2 \%)\end{array}$ \\
\hline $\begin{array}{l}\text { Respiratory exercises: } \\
\text { Deep breathing exercises } \\
\text { Tri-flow }\end{array}$ & $\begin{array}{l}8(16 \%) \\
2(4 \%)\end{array}$ & $\begin{array}{l}10(20 \%) \\
2(4 \%)\end{array}$ & $\begin{array}{l}11(20 \%) \\
2(4 \%)\end{array}$ & $\begin{array}{l}12(23 \%) \\
3(6 \%)\end{array}$ \\
\hline $\begin{array}{l}\text { Stretching: } \\
\text { Calf stretch } \\
\text { Psoas major stretch } \\
\text { Prone lie } \\
\text { Heel to opposite knee (supine) }\end{array}$ & $\begin{array}{l}1(2 \%) \\
1(2 \%) \\
1(2 \%) \\
1(2 \%)\end{array}$ & $\begin{array}{l}1(2 \%) \\
1(2 \%) \\
1(2 \%) \\
-\end{array}$ & $\begin{array}{l}1(2 \%) \\
1(2 \%) \\
1(2 \%) \\
1(2 \%)\end{array}$ & $\begin{array}{l}2(4 \%) \\
1(2 \%) \\
1(2 \%) \\
1(2 \%)\end{array}$ \\
\hline
\end{tabular}

Notes: * $n$, number of hospitals where physiotherapy intervention routinely included a post-operative exercise programme; TA, Transverse abdominus; $\mathrm{CL}$, crook lie; st, standing; SL, side lie; LL, Lower limb; flex, flexion; ext, extension; df, dorsiflexion; pf, plantarflexion; ROM, range of motion. 
Of the 56 physiotherapy services that routinely prescribed a post-operative exercise programme $88 \%$ (49/56) included exercise to target core stabilisation, 45\% (25/56) included lower limb circulation exercise, $45 \%$ (25/56) included strengthening exercise and 39\% (22/56) included exercise to improve spinal ROM. Fourteen respondents (25\%) reported including neural mobilisation, 18\% (10/56) included respiratory exercises and 5\% $(3 / 56)$ included stretching. There was little variation in the type of exercise prescribed based on the surgical procedure.

\section{Outcome measurement}

Patients were assessed using an outcome measurement tool at $83 \%(53 / 64)$ of the hospitals. Of the respondents that reported using at least one outcome measure, 96\% (51/53) reported assessing pain using a visual analogue or numeric pain rating scale, while only one hospital (2\%) reported using a scale designed to assess disability (Table 4).

Table 4: Outcome measurement

\begin{tabular}{ll}
\hline Outcome measurement tool & Reported use \\
\hline VAS/NPRS & $96 \%(51 / 53)$ \\
Straight leg raise & $38 \%(20 / 53)$ \\
Spinal range of motion & $9 \%(5 / 53)$ \\
$10 m$ walk test & $6 \%(3 / 53)$ \\
Oswestry Disability Index & $2 \%(1 / 53)$ \\
\hline
\end{tabular}

Notes: VAS, Visual analogue scale; NPRS, Numeric pain rating scale.

Referral to inpatient and outpatient physiotherapy/ rehabilitation services

Most respondents $(83 \%, 55 / 66)$ referred patients to an inpatient rehabilitation unit some of the time (Figure 3), with patient need (ie ongoing rehabilitation goals) being the main factor influencing this decision.

Half of the respondents $(49 \%, 33 / 67)$ referred patients to outpatient physiotherapy/rehabilitation some of the time (Figure 3). Patient need was again the main factor influencing this decision. Of the respondents that referred patients to outpatient physiotherapy $27 \%$ (14/51) advised to commence physiotherapy within the first two weeks post-operatively, 54\% (28/51) advised patients to commence physiotherapy between two and six weeks, and 19\% (10/51) advised to commence physiotherapy seven or more weeks following surgery.

\section{DISCUSSION}

This survey describes the current physiotherapy management of adults undergoing lumbar spinal surgery in Australian Hospitals. As a total population survey with a high response rate $(79 \%)$, the results of this survey are likely to be a fairly accurate reflection of physiotherapy management of this patient population.

\section{Physiotherapy service}

All hospitals provided a post-operative physiotherapy service, with minimal difference between the hospitals in the timing and frequency of the service provided. This finding is comparable to the results of previous surveys investigating physiotherapy practice following spinal surgery in the United Kingdom (Rushton et al 2014, Williamson et al 2007).

Less than half of the hospitals surveyed provided a preoperative physiotherapy service, and none of those provided a formal pre-operative rehabilitation programme. The scope of the questionnaire used in this survey does not allow for further interpretation of this observation, however there is some evidence to suggest that pre-operative rehabilitation may improve post-operative outcome (Nielsen et al 2010). Further investigation of the effect of pre-operative rehabilitation, and how to provide this service within the Australian healthcare system is warranted.

\section{Physiotherapy intervention}

The overall emphasis of physiotherapy intervention was consistent across the hospitals with a focus on patient education and post-operative mobility. All hospitals provided mobility and functional task training as part of the routine post-operative rehabilitation programme. Physiotherapy intervention included exercise prescription and the provision of educational handouts at most hospitals, however there was variability in the individual exercises prescribed and the advice given regarding movement and activity restrictions. These findings are again comparable to United Kingdom physiotherapy practice following lumbar discectomy (Williamson et al 2007) and lumbar fusion (Rushton et al 2014).

Despite the common focus on patient mobility, initial mobilisation was often delayed from the day of surgery, until the initial physiotherapy contact the day following surgery. While no research has investigated the relationship between mobilisation and patient recovery following spinal surgery, there is evidence to suggest that mobilising on the day of surgery improves both patient outcomes and length of stay in other inpatient surgical populations (Issac et al 2005, Kaneda et al 2007, Larsen et al 2008). It is therefore possible that starting a rehabilitation programme on the day of surgery, with a focus on patient mobility, may reduce the time to achieve functional milestones and reduce overall length of stay.

Core stabilisation exercise was the most common category of exercise prescribed, with transverse abdominus activation the most frequently prescribed exercise. Two recent systematic reviews concluded that core stabilisation exercises may reduce pain and disability in patients with sub-acute, chronic or recurrent low back pain (Brumitt et al 2013, Bystrom et al 2013), however, it is not known whether similar outcomes may be expected in the post spinal surgery population. With the exception of core stabilisation exercise, there was little agreement between the hospitals in the types of exercise prescribed. This lack of consistency likely reflects the limited evidence available to guide physiotherapists in both designing exercise programmes and timing the commencement of the exercise programme. It is also likely that exercise prescription was influenced by post-operative movement restrictions, which varied considerably between the hospitals.

Almost half the hospitals that routinely prescribed a postoperative exercise programme included lower limb circulation exercises, and $18 \%$ included respiratory exercises. Evidence suggests that patient mobilisation is adequate to prevent deep 
vein thrombosis following spinal surgery (Takahashi et al 2012), supported by similar findings in other post surgical populations (Chandrasekaran et al 2009, Pearse et al 2007). In addition, patient mobilisation has been shown to prevent post-operative pulmonary complications without the need for additional exercises (Denehy et al 2003, Silva 2013). As this survey demonstrates, the majority of patients mobilise either the day of or the day following surgery, therefore including these exercises in routine post-operative management may be unnecessary and warrants further evaluation.

Referral to outpatient physiotherapy following discharge was variable. While three quarters of hospitals reported referring patients to an outpatient physiotherapy service, only a third of these routinely referred all patients. Evidence suggests that rehabilitation commencing in the sub-acute phase following lumbar disc surgery improves patient outcome (Oosterhuis et al 2014) therefore further evaluation of referral to outpatient physiotherapy, including patient selection and access to outpatient physiotherapy services, is required. In addition, where no referral to outpatient physiotherapy occurs, intervention provided by the inpatient physiotherapist may have a positive influence on return to work and normal activity. This highlights the need for further research investigating the impact of physiotherapy interventions provided in the inpatient setting on long term patient outcome.

\section{Variation between surgical procedures}

Within each hospital, there was little difference in physiotherapy interventions provided across the different surgical procedures. This result likely reflects the focus of intervention being on mobility tasks, which are to be similar irrespective of the surgical procedure. It does, however, raise the question of whether interventions that are targeted to the specific surgical procedure may be more effective at optimising patient outcome within these groups.

\section{Influence of individual surgeon preferences on}

\section{physiotherapy practice}

Just over half of the hospitals with more than one spinal surgeon reported variation in physiotherapy intervention based on differences in surgeon preferences, with the main difference being in the post-operative advice provided to patients regarding movement and activity restriction. These results are consistent with previous surveys conducted with both physiotherapists (Williamson et al 2007) and spinal surgeons (McGregor et al 2006, Rushton et al 2015) in the United Kingdom.

Post-operative movement and activity restrictions are likely to influence the type of exercises prescribed in the post-operative period, education regarding mobility and functional tasks, and the advice given regarding return to work and usual activity. Patients were most commonly advised to restrict movement and activity for four to six weeks post-operatively, potentially delaying active rehabilitation and return to work during this period and leading to additional financial and social burden. Results from one study indicated there was no detrimental effect on patient outcome by having no post-operative restrictions following lumbar discectomy (Carragee et al 1999). While a proportion of the variation in post-operative advice is likely due to the criteria individual surgeons use to determine candidacy for surgery, further research is required to evaluate the necessity of post-operative restrictions and the impact they have on patient outcome in the short and long term.

\section{Outcome measurement}

Almost all hospitals reported assessing pain with only a very small number assessing physical function, however the correlation between pain and physical function following spinal surgery has been shown to be limited (DeVine et al 2011). In addition, only one hospital reported using an outcome measurement tool to assess disability despite an increasing focus on assessing disability and recovery of function in the clinical setting.

Current international guidelines for the management of low back pain recommend referral to a specialist anywhere between four weeks and two years after the onset of back pain, and only following a trial of conservative management (Koes et al 2010). It is therefore likely that the majority of patients undergoing lumbar spinal surgery have been living with considerable functional limitation for some time. The use of appropriate outcome measures assessing physical function pre and postoperatively would provide valuable information to guide return to work and other activities of daily living during the rehabilitation period.

\section{Clinical relevance}

The information collected from this survey provides a description of current physiotherapy practice in Australian hospitals. While there is consensus that this patient population benefits from physiotherapy intervention in this setting, there is considerable variation in the physiotherapy interventions provided, an observation consistent with United Kingdom physiotherapy practice following lumbar discectomy (Williamson et al 2007) and lumbar fusion (Rushton et al 2014). This finding likely reflects the limited research available to guide clinicians working in the acute hospital setting. This information should therefore be used to inform clinicians about current practice, but not be regarded as "gold standard". Further research is required to develop clear rehabilitation guidelines to facilitate optimal outcome for patients undergoing lumbar spinal surgery.

\section{Study limitations}

Using a structured questionnaire format with predominantly closed questions and pre-determined response categories allowed for the collection of data across a range of categories within a short timeframe. However, it also limited participant responses with minimal opportunity to elaborate on answers provided. Several areas of current practice requiring further analysis have been identified, including referral processes to outpatient physiotherapy services and the use of outcome measures in standard practice. Additional information regarding the influence of pre-operative diagnosis and symptoms, patient age, and co-morbidities on the choice of interventions provided may also have allowed for a more in depth analysis of data.

Publicly and privately funded hospitals were equally represented in the responding hospitals, while most (82\%) of the nonresponding hospitals were privately funded. It is possible that data from the non-responding hospitals may have influenced the results of this survey, however due to the variability in responses received it is likely that the overall conclusions of this study would remain unchanged. 


\section{CONCLUSION}

This survey demonstrates considerable variability in physiotherapy management of patients following lumbar spinal surgery, which likely reflects the paucity of research investigating the relationship between peri-operative physiotherapy intervention and patient outcome. This survey provides physiotherapists and health service managers with information regarding current clinical practice, and identifies the key focus areas for future research into the effectiveness of physiotherapy interventions for people undergoing spinal surgery.

\section{KEY POINTS}

1. Almost all patients undergoing lumbar spinal surgery in Australia are seen by a physiotherapist during their hospital admission, with the overall goals of physiotherapy intervention focusing on patient education, post-operative mobility and exercise prescription.

2. Physiotherapy intervention does not vary based on the type of surgical procedure undertaken.

3. Surgeon specific protocols guide post-operative restrictions, and therefore influence the structure and timing of the physiotherapy rehabilitation programme.

4. There is limited use of outcome measurement tools to assess physical function in the acute setting following lumbar spinal surgery.

\section{DISCLOSURES}

The authors declare that no financial support was obtained to undertake this study. The authors report no conflicts of interes

\section{ADDRESS FOR CORRESPONDENCE}

Sarah Gilmore, St Vincent's Private Hospital Melbourne, 59 Victoria Parade, Fitzroy, 3065, VIC, Australia. Email: sarah. gilmore@svha.org.au. Telephone: 0061394117546

\section{REFERENCES}

Brumitt J, Matheson JW, Meira EP (2013) Core stabilization exercise prescription, Part 2: A systematic review of motor control and general (global) exercise rehabilitation approaches for patients with low back pain. Sports Health 5:510-513. doi:10.1177/1941738113502634.

Bystrom MG, Rasmussen-Barr E, Grooten WJA (2013) Motor control exercises reduce pain and disability in chronic and recurrent low back pain: a metaanalysis. Spine 38:E350-E358. doi:10.1097/BRS.0b013e31828435fb.

Carragee EJ, Han MY, Yang BBS, Kim DH, Kraemer H, Billys J (1999) Activity restrictions after posterior lumbar discectomy: a prospective study of outcomes in 152 cases with no postoperative restrictions. Spine 24:2346.

Chandrasekaran S, Ariaretnam SK, Tsung J, Dickison D (2009) Early mobilization after total knee replacement reduces the incidence of deep venous thrombosis. ANZ Journal of Surgery 79:526-529. doi:10.1111/ j.1445-2197.2009.04982.x

Denehy L, Brasher PA, Story I, McClelland KH (2003) Does removal of deep breathing exercises from a physiotherapy program including pre-operative education and early mobilisation after cardiac surgery alter patient outcomes? Australian Journal of Physiotherapy 49:165-173. doi:10.1016/ S0004-9514(14)60236-1.

DeVine J, Norvell DC, Ecker E, Fourney DR, Vaccaro A, Wang J, Andersson G (2011) Evaluating the Correlation and Responsiveness of Patient-Reported Pain With Function and Quality-of-Life Outcomes After Spine Surgery. Spine 36:S69-S74. doi:10.1097/BRS.0b013e31822ef6de.
Gideon L (2012) Handbook of Survey Methodology for the Social Sciences. Dordrecht: Springer.

Gilmore SJ, McClelland JA, Davidson M (2015) Physiotherapeutic interventions before and after surgery for degenerative lumbar conditions: a systematic review. Physiotherapy 101:111-8. doi:10.1016/j. physio.2014.06.007.

Harris IA, Dao AT (2009) Trends of spinal fusion surgery in Australia: 1997 to 2006. ANZ Journal of Surgery 79:783-8. doi:10.1111/j.14452197.2009.05095.x.

Isaac D, Falode T, Liu P, L'Anson H, Dillow K, Gill P (2005) Accelerated rehabilitation after total knee replacement. The Knee 12:346-350. doi:10.1016/j.knee.2004.11.007.

Kaneda H, Saito Y, Okamoto M, Maniwa T, Minami K, Imamure H (2007) Early postoperative mobilization with walking at 4 hours after lobectomy in lung cancer patients. General Thoracic and Cardiovascular Surgery 55:493-498.

Koes BW, van Tulder M, Lin CC, Macedo LG, McAuley J, Maher C. (2010) An updated overview of clinical guidelines for the management of nonspecific low back pain in primary care. European Spine Journal 19:20752094. doi:10.1007/s00586-010-1502-y.

Larsen K, Sørensen OG, Hansen TB, Thomsen PB, Soballe K (2008) Accelerated perioperative care and rehabilitation intervention for hip and knee replacement is effective: A randomized clinical trial involving 87 patients with 3 months of follow-up. Acta Orthopaedica 79:149-159. doi:10.1080/17453670710014923.

McGregor A, Dicken B, Jamrozik K (2006) National audit of post-operative management in spinal surgery. BMC Musculoskeletal Disorders 7:47. doi:10.1186/1471-2474-7-47

National Health Performance Authority MyHospitals. Available at: http:// www.myhospitals.gov.au. [Accessed 19 May, 2013].

Nielsen PR, Jorgensen LD, Dahl B, Pedersen T, Tonnesen H (2010) Prehabilitation and early rehabilitation after spinal surgery: randomized clinical trial. Clinical Rehabilitation 24:137-148. doi:10.1177/0269215509347432.

Oosterhuis T, Costa Leonardo OP, Maher Christopher G, de Vet HCW, van Tulder MW, Ostelo RWJG (2014) Rehabilitation after lumbar disc surgery. Cochrane Database of Systematic Reviews. doi:10.1002/14651858. CD003007.pub3

Pearse EO, Caldwell BF, Lockwood RJ, Hollard J (2007) Early mobilisation after conventional knee replacement may reduce the risk of postoperative venous thromboembolism. Journal of Bone and Joint Surgery, British Volume 89-B:316-322. doi:10.1302/0301-620X.89B3.18196.

Rajaee SS, Bae HW, Kanim LE, Delamarter RB (2012) Spinal fusion in the United States: analysis of trends from 1998 to 2008. Spine 37:67-76. doi:10.1097/BRS.0b013e31820cccfb.

Rushton A, Heneghan N, Heap A, White L, Eveleigh G, Wright C (2014) Survey of current physiotherapy practice for patients undergoing lumbar spinal fusion in the UK. Spine 39:E1380-E1387. doi:10.1097/ BRS.0000000000000573.

Rushton A, White L, Heap A, Heneghan N (2015) Evaluation of current surgeon practice for patients undergoing lumbar spinal fusion surgery in the United Kingdom. World Journal of Orthopedics 6:483-490. doi:10.5312/wjo.v6.i6.483.

Silva YR, Li SK, Rickard MJFX (2013) Does the addition of deep breathing exercises to physiotherapy-directed early mobilisation alter patient outcomes following high-risk open upper abdominal surgery? Cluster randomised controlled trial. Physiotherapy 99:187-193. doi:10.1016/j. physio.2012.09.006.

Takahashi H, Yokoyama Y, lida Y, Terashima F, Hasegawa K, Saito T, Suguro T, Wada A (2012) Incidence of venous thromboembolism after spine surgery. Journal of Orthopaedic Science 17:114-7. doi:10.1007/s00776-011-01882.

Williamson E, White L, Rushton A (2007) A survey of post-operative management for patients following first time lumbar discectomy. European Spine Journal 16:795-802. doi:10.1007/s00586-006-0207-8. 